\title{
Reducing radiation exposure using commonly available objects
}

\author{
Daisuke Kobayashi • Masao Miyake • Takeyasu Kakamu • \\ Masayoshi Tsuji • Yayoi Mori · Tetsuhito Fukushima • \\ Akihiro Hazama
}

Received: 29 September 2012/ Accepted: 11 October 2012/Published online: 4 November 2012

(C) The Japanese Society for Hygiene 2012

\begin{abstract}
Objectives One and a half years have passed since the Fukushima Daiichi nuclear power plant disaster. The environmental radiation dose rate was not critical, but an existing exposure situation has been identified in a large part of Fukushima Prefecture. Although people continue to live and work in the contaminated area, they are not provided with sufficient information to reduce their exposure to radiation by themselves. In this study, we attempt to evaluate the efficiency of radiation shielding by using everyday items widely available to people.

Methods NaI scintillation and Geiger-Müller survey meters were used to measure the radiation dose of (1) contaminated soil and (2) soil covered with commonly available items.

Results In the soil at a depth of $10 \mathrm{~cm}$ from the surface, the radiation dose rate decreased from 3.36 to $0.65 \mu \mathrm{Sv} / \mathrm{h}$, and the count rate decreased from 3,120 to $352 \mathrm{cpm}$. Both the radiation dose rate and count rate reduced when the soil was covered with everyday items, such as a magazine more than $20 \mathrm{~mm}$ thick, a polystyrene foam board, and a wooden board of the same thickness.

Conclusions To protect residents from unnecessary radiation exposure in the existing exposure situation, covering contaminated soil with a wooden board or a magazine,
\end{abstract}

D. Kobayashi $(\bowtie) \cdot$ M. Miyake · A. Hazama

Department of Cellular and Integrative Physiology,

School of Medicine, Fukushima Medical University,

1 Hikarigaoka, Fukushima 960-1295, Japan

e-mail: coba@fmu.ac.jp

T. Kakamu - M. Tsuji · Y. Mori · T. Fukushima Department of Hygiene and Preventive Medicine, School of Medicine, Fukushima Medical University, Fukushima, Japan either of them $20 \mathrm{~mm}$ thick, is useful to reduce the radiation dose.

Keywords Fukushima Daiichi nuclear power plant disaster - Radiation dose $\cdot$ Radiation protection $\cdot$ Reduction of radiation dose $\cdot$ Shielding

\section{Introduction}

On 11 March 2011, a tsunami caused by an earthquake off the Pacific coast of Tohoku devastated the Fukushima Daiichi nuclear power plant, and the subsequent loss of the cooling system and a hydrogen explosion led to the release of radioactive materials. The radioactive materials diffused over the entire Tohoku region, including the Fukushima Prefecture and Kanto region. According to the report released by the Ministry of Education, Culture, Sports, Science, and Technology (MEXT) on 21 March 2012, the accumulated dose in most of the City of Fukushima was higher than the total annual global effective dose due to natural radiation sources as estimated by the United Nations Scientific Committee on the Effects of Atomic Radiation (UNSCEAR) [1-3]. The accumulated radiation dose from March 2011 to March 2012 calculated by MEXT was from 2.3 to $10.1 \mathrm{mSv}$ [1]. The high effective dose in Fukushima City was considered to be due to radioactive contaminated soil. At the time of the disaster, the major radionuclides that widely diffused were tellurium-132, iodine-131 (I-131), iodine132, cesium-134 (Cs-134), cesium-137 (Cs-137), and xenon-138 [4]. Six months after the disaster, the main source of the radiation dose rate in Fukushima was assumed to be radioactive cesium (Cs-134 and Cs-137) in the ground $[5,6]$. 
On the basis of the principles of radiation protection, evacuation from a contaminated area is the best way to reduce unnecessary radiation exposure. Residents living within a $20-\mathrm{km}$ radius of the nuclear power plant were evacuated soon after the disaster. However, people living outside the evacuation zone continue to live and work in Fukushima Prefecture. The International Commission on Radiological Protection (ICRP) states that a postaccident rehabilitation situation is considered to be like an "existing exposure situation" [7]. It is reasonable that people want to avoid unnecessary exposure as much as possible, even though they are not in an emergency exposure situation.

Methods that use materials to reduce the radiation dosage are widely known in the literature, but such information was usually obtained from experiments under a controlled situation. In other words, the information includes the sum of physical parameters obtained from the controlled experiments, not taking into account a variety of situations, such as the living environment. People in Fukushima live in a contaminated area where the exact identification of radioactive materials is still undetermined. However, now, they do have access to information about the radiation dose rate in their own community as well as in neighboring areas. Checking the radiation dose rate is the easiest way to understand the current status of unnecessary radiation exposure. In this study, we suggest how to reduce the radiation dose through self-help protection. It is necessary for all citizens to keep in mind how to protect themselves against radioactive materials and fallout whenever a nuclear accident occurs.

\section{Methods}

Measuring equipment

The radiation dose rate $(\mu \mathrm{Sv} / \mathrm{h})$ of $\gamma$-rays was measured using an NaI scintillation survey meter (TCS-172; Aloka, Tokyo), and the count rate (cpm) of $\beta$-rays and $\gamma$-rays was measured using a Geiger-Müller (GM) survey meter (TGS136; Aloka, Tokyo) [8, 9].

\section{Outdoor experiments}

Measurement of the radiation dose rate and count rate of the ground surface were carried out at $1 \mathrm{~cm}$ above the ground surface on Thursday 14 April 2011, at Fukushima Medical University $\left(37^{\circ} 410 \mathrm{~N}, 140^{\circ} 280 \mathrm{E}\right)$, located at $57.8 \mathrm{~km}$ west-northwest of the Fukushima Daiichi nuclear power plant $\left(37^{\circ} 250 \mathrm{~N}, 141^{\circ} 020 \mathrm{E}\right)$ [8]. The measurement instruments were held by hand, horizontal to the ground surface, and the radiation dose rate was recorded $1 \mathrm{~min}$ after the survey meter was positioned. Vertical-direction measurements were carried out after stripping each layer of soil at $1,2,3,4,5$, and $10 \mathrm{~cm}$ below the ground surface $(20 \mathrm{~cm} \times 20 \mathrm{~cm}$ area $)$.

\section{Indoor experiment}

On Monday 18 April 2011, we collected soil from a site where rainwater collects; it had a radiation dose rate of over $30 \mu \mathrm{Sv} / \mathrm{h}$ (the upper limit of the measuring instrument) and a count rate of 22,200 cpm [8]. To prepare a model ground surface, we filled a plastic dish $(115 \mathrm{~mm}$ diameter, $10 \mathrm{~mm}$ deep) with the collected soil as a radiation source. When packaging the soil, we treated it carefully and wrapped it with plastic film to avoid further contamination, then we sealed the plastic dish. The indoor experiment was carried out on 6 October 2011. On that day, it was expected that deposited radioactive materials with short half-life had mostly decayed $[6,9]$. Using both the NaI scintillation survey meter and GM survey meter, we measured the radiation from the soil in the dish. Both measurements were carried out simultaneously with the survey meters in contact with the dish's surface. The radiation dose rate was recorded when the value shown by the $\mathrm{NaI}$ scintillation survey meter became stable, and the count rate was recorded $1 \mathrm{~min}$ after we started recording the measurements with the GM survey meter. All indoor experiments were carried out at a place where the background radiation dose rate was $0.07 \pm 0.01 \mu \mathrm{Sv} / \mathrm{h}$ and count rate was $78 \pm 8 \mathrm{cpm}$. The mean value of the background radiation dose rate and count rate were subtracted from that of the model ground surface radiation dose rate and count rate. The materials tested were as follows: a newspaper, a piece of corrugated cardboard, a magazine as a sample of paper, and a sheet of polystyrene foam. We also used various samples of cloth: one made from a blend of polyester and cotton (65:35), one from a sheet of polyethylene, one from a ethylene-vinyl acetate blend, one from a blend of cotton and polyurethane (95:5), and one from $100 \%$ cotton. Other materials included a cork board, a wooden board made from Betula (birch), and an aluminum board. These materials are easily available in most markets in Japan.

\section{Results}

In the results of this study, the radiation dose rate measured by the NaI scintillation survey meter indicates the effect of $\gamma$-rays, and the count rate measured by the GM survey meter indicates the effect of the sum of $\beta$-rays and $\gamma$-rays.

\section{Outdoor experiments}

To understand the status of soil contamination on 14 April 2011, which was approximately 1 month after the 
explosion of the Fukushima Daiichi nuclear power plant, the ground surface radiation dose rate and count rate were measured at $1 \mathrm{~cm}$ above the ground surface. The base measurement was carried out using the $\mathrm{NaI}$ scintillation survey meter and GM survey meter, and the values recorded were $3.36 \mu \mathrm{Sv} / \mathrm{h}$ and $3,120 \mathrm{cpm}$, respectively. Subsequently, we collected a $20-\mathrm{cm}^{2}$ area of the soil surface and exposed a 1-cm-deep underground layer. The radiation dose rate and count rate of the underground layer were measured at $1 \mathrm{~cm}$ above the surface. We continued to expose additional layers at depths of 2, 3, 4, 5, and $10 \mathrm{~cm}$ (Fig. 1). For each exposed layer, we measured the radiation dose rate and count rate. Both measurements decreased as the depth increased. In the soil at a depth of $10 \mathrm{~cm}$, the radiation dose rate decreased to $0.65 \mu \mathrm{Sv} / \mathrm{h}$, approximately one-fifth of the surface radiation dose rate, and the count rate decreased to $352 \mathrm{cpm}$, approximately one-tenth of the surface count rate. Each collected soil layer was mixed with the others, and the mixed soil was returned to the soil removal location. Thereafter, the radiation dose rate and count rate of the ground surface were measured again. These rates were found to be decreased to $2.37 \mu \mathrm{Sv} / \mathrm{h}$ and $1,415 \mathrm{cpm}$, respectively.

\section{Indoor experiments}

Soil was collected and packed in a plastic laboratory dish for use as a model radiation source. The dish was sealed tightly and wiped to avoid further contamination. We measured the radiation dose rate and count rate with the survey meters in contact with the surface of the dish containing the contaminated soil. The value for the model radiation source was $12.9 \mu \mathrm{Sv} / \mathrm{h}$, with count rate of $7,752 \mathrm{cpm}$. During the indoor experiments, using the dish soil as a model of the contaminated ground surface, we evaluated how effectively various everyday items can shield radiation. The radiation dose rate and count rate of

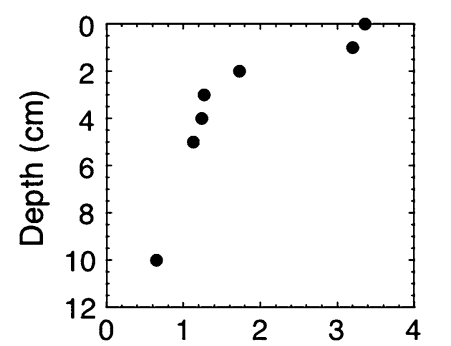

Radiation dose rate $(\mu \mathrm{Sv} / \mathrm{h})$

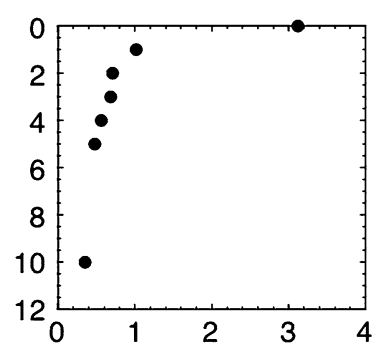

Count rate $\left(\times 10^{3} \mathrm{cpm}\right)$
Fig. 1 Depth profiles of radiation dose rates and count rates in field soil at Fukushima Medical University on 14 April 2011. The radiation dose rates and count rates were measured using a $\mathrm{NaI}$ scintillation survey meter (TCS-172) and a Geiger-Müller survey meter (TGS136), respectively the surface of dish were measured after covering it with each object described above (see "Methods"). Then, the measured value was compared with measurements taken when the dish was not covered. Table 1 presents means of five measurements. The reduction coefficient of the radiation dose rate was calculated by dividing the radiation dose rate of the model ground surface covered with the shielding material by the rate without the shielding material. The reduction coefficients of the radiation dose rate and count rate were obtained. The reduction coefficient of the radiation dose rate and that of count rate had a tendency to decline according to the thickness of the covering material, irrespective of what it was made from. In this study, the radiation dose rate and count rate decreased by approximately $50 \%$ when the thickness of the shielding materials (either the magazine, two layers of 10-mm polystyrene foam board, or two layers of 10-mm Betula wood board) was $20 \mathrm{~mm}$ or greater. In addition, even though several types of cloth with four layers were used as shielding objects, their efficiency to shield the radiation dose rate was below $10 \%$. The polyethylene cloth had less shielding efficiency than the other cloth materials.

When comparing the reduction coefficient of the count rate and that of the radiation dose rate, there was a more significant decrease in the count rate than in the radiation dose rate. In general, $\beta$-rays were absorbed by shielding materials more than $\gamma$-rays. It is natural that the mean values of the count rate decreased more drastically than those of the radiation dose rate.

The shielding materials used in this study were categorized into three groups: (1) wood, including paper made from wood, (2) synthetic fibers, and (3) aluminum. Assuming that paper is a type of wood, the apparent attenuation coefficient of wood was estimated using the following equation:

$I=I_{0} \exp (-\mu t)$,

where $I$ is the intensity of the radiation dose rate when shielded by wood, $I_{0}$ is the intensity of the radiation dose rate without shielding, $\mu$ is the apparent attenuation coefficient for wood, and $t$ is the thickness of wood or paper. The mean values of the radiation dose rate of paper and wood are plotted in Fig. 2 and were substituted into Eq. 1. The calculated apparent attenuation coefficient for wood was 0.044 when the model ground soil was used as the radiation source. The thickness of wood used in the experiments has an attenuated radiation dose rate from 50 to $90 \%$. Therefore, $t_{1 / 2}$ and $t_{1 / 10}$ were estimated to be 15.8 and $52.3 \mathrm{~mm}$, respectively, based on Eqs. 2 and 3 .

$t_{1 / 2}=\ln (2) \mu^{-1}$,

$t_{1 / 10}=\ln (10) \mu^{-1}$. 
Table 1 Comparison of surface radiation dose rates and count rates of contaminated soil when shielded by various materials

\begin{tabular}{|c|c|c|c|c|c|}
\hline \multirow[t]{2}{*}{ Material } & \multirow{2}{*}{$\begin{array}{l}\text { Thickness } \\
(\mathrm{mm})\end{array}$} & \multicolumn{2}{|c|}{ Radiation dose rate $(\mu \mathrm{Sv} / \mathrm{h})$} & \multicolumn{2}{|l|}{ Count rate (cpm) } \\
\hline & & Mean \pm SD & $\begin{array}{l}\text { Reduction } \\
\text { coefficient }\end{array}$ & Mean \pm SD & $\begin{array}{l}\text { Reduction } \\
\text { coefficient }\end{array}$ \\
\hline Contaminated soil & & $13.0 \pm 0.1$ & 1.00 & $7,752 \pm 29$ & 1.00 \\
\hline \multicolumn{6}{|l|}{ Paper } \\
\hline Newspaper (16-sheet) & 1 & $12.0 \pm 0.1 * *$ & 0.92 & $6,662 \pm 121^{* *}$ & 0.86 \\
\hline Corrugated cardboard & 4 & $9.99 \pm 0.08 * *$ & 0.77 & $5,457 \pm 99 * *$ & 0.70 \\
\hline Two layers & 8 & $8.46 \pm 0.04 * *$ & 0.65 & $4,672 \pm 559 * *$ & 0.60 \\
\hline Magazine & 25 & $4.61 \pm 0.03^{* *}$ & 0.35 & $2,094 \pm 89 * *$ & 0.27 \\
\hline \multicolumn{6}{|l|}{ Polystyrene foam board } \\
\hline & 10 & $8.08 \pm 0.14 * *$ & 0.62 & $4,658 \pm 63^{* *}$ & 0.60 \\
\hline Two layers & 20 & $5.07 \pm 0.09 * *$ & 0.39 & $3,254 \pm 45^{* *}$ & 0.42 \\
\hline \multicolumn{6}{|l|}{ Cloth } \\
\hline Polyester:cotton $=65: 35$ & 0.3 & $12.4 \pm 0.1^{*}$ & 0.95 & $7,326 \pm 72 * *$ & 0.94 \\
\hline Two layers & 0.6 & $12.4 \pm 0.1 *$ & 0.95 & $7,015 \pm 22 * *$ & 0.90 \\
\hline Four layers & 1.2 & $12.1 \pm 0.1 * *$ & 0.93 & $6,637 \pm 74 * *$ & 0.86 \\
\hline Polyethylene & 0.1 & $13.0 \pm 0.1$ & 1.00 & $7,595 \pm 51 * *$ & 0.98 \\
\hline Two layers & 0.2 & $12.8 \pm 0.1$ & 0.98 & $7,469 \pm 122^{*}$ & 0.96 \\
\hline Four layers & 0.4 & $12.6 \pm 0.2 *$ & 0.96 & $7,115 \pm 24 * *$ & 0.92 \\
\hline Ethylene-vinyl acetate & 0.1 & $12.5 \pm 0.1 *$ & 0.96 & $7,585 \pm 32 * *$ & 0.98 \\
\hline Two layers & 0.2 & $12.6 \pm 0.1 *$ & 0.96 & $7,549 \pm 82^{*}$ & 0.97 \\
\hline Four layers & 0.4 & $11.7 \pm 0.1 * *$ & 0.90 & $7,177 \pm 63^{* *}$ & 0.93 \\
\hline Cotton:polyurethane $=95: 5$ & 0.2 & $12.6 \pm 0.1 *$ & 0.97 & $7,195 \pm 59 * *$ & 0.93 \\
\hline Two layers & 0.4 & $12.6 \pm 0.1 *$ & 0.97 & $6,996 \pm 51 * *$ & 0.90 \\
\hline Four layers & 0.8 & $12.2 \pm 0.1^{* *}$ & 0.94 & $6,601 \pm 79 * *$ & 0.85 \\
\hline Cotton & 0.3 & $12.7 \pm 0.3$ & 0.98 & $7,405 \pm 36^{* *}$ & 0.96 \\
\hline Two layers & 0.6 & $12.4 \pm 0.2$ & 0.95 & $7,164 \pm 98 * *$ & 0.92 \\
\hline Four layers & 1.2 & $12.2 \pm 0.2 *$ & 0.94 & $6,571 \pm 175^{* *}$ & 0.85 \\
\hline \multicolumn{6}{|l|}{ Wood } \\
\hline \multirow[t]{3}{*}{ Cork } & 1.3 & $11.7 \pm 0.2^{* *}$ & 0.90 & $6,653 \pm 91 * *$ & 0.86 \\
\hline & 6 & $9.55 \pm 0.06^{* *}$ & 0.73 & $5,099 \pm 445^{* *}$ & 0.66 \\
\hline & 10 & $8.00 \pm 0.10^{* *}$ & 0.61 & $4,315 \pm 93^{* *}$ & 0.56 \\
\hline Betula (birch) & 10 & $7.58 \pm 0.03^{* *}$ & 0.58 & $4,044 \pm 33^{* *}$ & 0.52 \\
\hline Two layers & 20 & $5.25 \pm 0.10^{* *}$ & 0.40 & $2,793 \pm 43 * *$ & 0.36 \\
\hline Aluminum sheet & 3 & $9.32 \pm 0.09 * *$ & 0.72 & $5,345 \pm 61 * *$ & 0.69 \\
\hline
\end{tabular}

Mean \pm standard deviation (SD) is indicated $(n=5) ; * p<0.01$ and $* * p<0.001$ compared with contaminated soil by Student's $t$ test. The reduction coefficient was calculated by dividing the radiation dose rate and count rate of the model ground surface when shielded with materials by those rates without shielding

\section{Discussion}

On 14 April 2011, radioactive fallout was deposited on the ground surface, but it did not penetrate deeply into the ground (Fig. 1). The depth profiles of the radiation dose rate and count rate were different. The count rate decreased by approximately $30 \%$ when $1 \mathrm{~cm}$ of ground surface was removed, but the radiation dose rate did not. The difference was assumed to be due to $\gamma$-ray and $\beta$-ray detector directivity. The GM survey meter detected $\beta$-rays almost from one direction, because the detector window was in front of the probe. Conversely, the NaI scintillation survey meter was able to detect radiation from all directions around the probe. Because the probe was not protected by any shielding materials, such as lead, from rays coming from the surrounding area, the NaI probe detected not only radiation coming from in front of the probe but also radiation coming from the area surrounding the probe. In the case of experimental farmland soil at the National Institute for Agro-Environmental Sciences, Tsukuba, Ibaraki, Japan, 


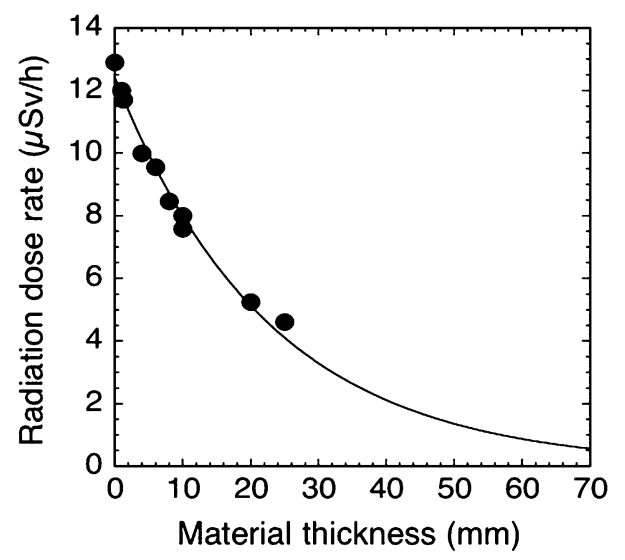

Fig. 2 The radiation dose rate was attenuated depending on the thickness of various materials. The materials included newspaper, corrugated cardboard, a magazine, cork, and a board of Betula (birch), all made from wood. The apparent attenuation coefficient for wood was estimated using the equation $I=I_{0} \exp (-\mu t)$, where $I$ is the intensity of the radiation dose rate with shielding, $I_{0}$ is the intensity of the radiation dose rate without shielding, $\mu$ is the apparent attenuation coefficient for wood, and $t$ is the material thickness

most of the radionuclides were accumulated within a few centimeters of the soil surface, and after tillage, the concentration of radionuclides within a few centimeters of the soil surface substantially decreased [10]. In fact, in the City of Koriyama in Fukushima Prefecture, the topsoil of sports grounds was removed to a depth of $3 \mathrm{~cm}$ at public elementary schools, achieving a substantial decrease in the radiation dose rate from 4.5 to $0.9 \mu \mathrm{Sv} / \mathrm{h}$ at $1 \mathrm{~cm}$ above the ground [11]. Therefore, removing the topsoil to a depth of $5 \mathrm{~cm}$ removed the contaminated soil and, therefore, lowered the radiation dosage. Topsoil perturbation to a depth of $10 \mathrm{~cm}$ reduced the radiation dose rate by approximately $30 \%$ and the count rate by approximately $55 \%$. The difference between these percentages is due to the properties of $\gamma$-rays and $\beta$-rays. We considered that the $\beta$-rays measured by the GM survey meter were decreased more by soil particles than the $\gamma$-rays measured by the $\mathrm{NaI}$ scintillation survey meter. When the radioactive fallout was diluted by topsoil perturbation, the $\beta$-rays were shielded by the soil layer while the $\gamma$-rays penetrated through the layer. A countermeasure used to lower radiation exposure is to remove topsoil where radioactive fallout was deposited or to dilute the topsoil by surface perturbation. Fundamentally, the former is the best way to lower the radiation exposure and protect people from unnecessary exposure. Although the Ministry of Agriculture, Forestry, and Fisheries reported the same results as in our test, soil perturbation was less effective in the area where the soil contained over $10,000 \mathrm{~Bq} / \mathrm{kg}$ of radioactive material $[12,13]$.

According to the report "Monitoring Information of Environmental Radioactivity Level," provided by MEXT 2 months after the disaster, at least some of the radionuclides, such as I-131, Cs-134, Cs-137, Te-129m, Te-132, and Sr-89, were detected at Sugitsuma, Fukushima, which is located $62 \mathrm{~km}$ northwest of the Fukushima Daiichi nuclear power plant. In particular, the concentrations of I-131, Cs-134, and Cs-137 were high [14]. It was assumed that the main radiation sources, $\beta$-rays and $\gamma$-rays, were deposited on the ground surface as radioactive fallout. Radioactive iodine was the radionuclide that affected human health the most right after the disaster. Considering that the half-life of radioactive iodine (I-131) is short (i.e., 8 days), after 1 month from the disaster, the concentration of I-131 in the ground soil was speculated to decrease to approximately one-tenth. In fact, a gamma radiation measurement began on 15 April 2011 [6]. Thereafter, the counts seemed to attenuate exponentially. After 6 months, the environmental radiation dose rate, measured at $100 \mathrm{~cm}$ above the soil surface, reduced by about $50 \%$ [9]. Radionuclides with long half-lives were predominant as the environmental radiation source. It was considered that, in present-day measurements, Cs-134 and Cs-137 have a larger effect as a radiation source than I-131.

One of the radiation protection principles is the use of interventions to reduce exposure. The ICRP proposed that radiation exposure must be kept as low as reasonably achievable, taking economic and social factors into account [15]. Although administrative support is essential for decontamination of a community's living environment, it is also important that civilians protect themselves from radiation exposure. In the indoor experiment in this study, we evaluated how effectively familiar everyday items could be used to shield people from radiation. Shielding by wood and paper with thickness of approximately $20 \mathrm{~mm}$ proved useful for reducing radiation due to radioactive fallout from the Fukushima Daiichi nuclear power plant. The results imply that covering contaminated soil with a 20-mm-thick wooden board or magazine protects the living environment of a contaminated garden or ground. Moreover, the apparent attenuation coefficient for wood covering contaminated soil in Fukushima reveals that $\sim 50$-mm-thick wood, including paper, reduces the radiation dose rate to almost one-tenth. The apparent attenuation coefficient for wood in this study is not officially approved as a parameter in nuclear physics; however, this type of information is useful for people actually living in a contaminated environment.

Next, we evaluated whether the radiation dose can be reduced by wearing everyday clothes. Two or more layers of cloth were not capable of sufficiently reducing the radiation dose due to contaminated soil. Although covering the soil surface with cloth was less effective in lowering the radiation dose, it was effective in preventing dispersion of radioactive material contained in dust. This type of information is more important to those who actually live in the 
radioactive contaminated environment. It is important to propose how to protect them from unnecessary radiation exposure by utilizing everyday items.

Acknowledgments The authors would like to thank Dr. H. Tsukada for comments on this paper and Enago (http://www.enago.jp) for English language review.

Conflict of interest The authors declare that they have no conflict of interest.

\section{References}

1. Ministry of Education, Culture, Sports, Science, and Technology. Release of the Accumulated Dose Estimations for the Period from March 11, 2011, to March 11, 2012, at Points where Measurements Have been Carried out Continuously. 2011. http://radioactivity.mext.go.jp/en/contents/5000/4651/24/ E255_0321_18.pdf. Accessed 27 July 2012.

2. Charies M. Sources and effects of ionizing radiation. J Radiol Prot. 2001;21:83-6.

3. United Nations Scientific Committee on the Effects of Atomic Radiation. UNSCEAR 2000 Report to the General Assembly, with scientific annexes volume I: Sources, Annex B: Exposures from natural radiation sources. 2000.

4. Matsumura H, Saito K, Ishioka J, Uwamino T. Diffusion of radioactive materials from Fukushima Daiichi Nuclear Power Station obtained by gamma-ray measurements on expressways. Trans Atom Energy Soc Jpn. 2011;10:152-62 (article in Japanese with English abstract).

5. González AJ. The recommendations of the ICRP vis-á-vis the Fukushima Dai-ichi NPP accident aftermath. J Radiol Prot. 2012;32:N1-7.

6. Kobayashi T. Radiation measurements at the campus of Fukushima Medical University through the 2011 earthquake off the Pacific coast of Tohoku and subsequent nuclear power plant crisis. Fukushima J Med Sci. 2011;57:70-4.
7. ICRP. Application of the Commission's Recommendations to the Protection of People Living in Long-term Contaminated Areas After a Nuclear Accident or a Radiation Emergency. ICRP Publication 111, Ann ICRP, 2009;39(3).

8. Tsuji M, Kanda H, Kakamu T, Kobayashi D, Miyake M, Hayakawa T, et al. An assessment of radiation doses at an educational institution $57.8 \mathrm{~km}$ away from the Fukushima Daiichi nuclear power plant one month after the nuclear accident. Environ Health Prev Med. 2012;17:124-30.

9. Kakamu T, Kanda H, Tsuji M, Kobayashi D, Miyake M, Hayakawa T, et al. Differences in rates of decrease of environmental radiation dose rates by ground surface property in Fukushima city after the Fukushima Daiichi nuclear power plant accident. Health Phys. 2013 (in press).

10. Yamaguchi N, Eguchi S, Fujiwara H, Hayashi K, Tsukada H. Radiocesium and radioiodine in soil particles agitated by agricultural practices: field observation after the Fukushima nuclear accident. Sci Total Environ. 2012;425:128-34.

11. Koriyama City, Fukushima Prefecture. Information about the disaster of the Tokyo Electric Power Company's Fukushima Daiichi Nuclear Power Station. 2011. http://www.city.koriyama. fukushima.jp/pcp_portal/PortalServlet?DISPLAY_ID=DIRECT\& NEXT_DISPLAY_ID=U000004\&CONTENTS_ID=23269. Accessed 27 July 2012 (in Japanese).

12. Ministry of Agriculture, Forestry, and Fisheries. Announcement of appropriate decontamination methods of farmland. 2011. http://www.maff.go.jp/j/kanbo/joho/saigai/jyosen/joho/pdf/ 111020-a2.pdf. Accessed 27 July 2012 (in Japanese).

13. Agriculture, Forestry, and Fisheries Research Council of the Ministry of Agriculture, Forestry, and Fisheries of Japan. About radioactive material elimination techniques of agricultural soil. 2011. http://www.s.affrc.go.jp/docs/press/110914.htm. Accessed 27 July 2012 (in Japanese).

14. Ministry of Agriculture, Forestry, and Fisheries. Results of soil monitoring. 2011. http://radioactivity.mext.go.jp/old/ja/monitoring around_FukushimaNPP_soil_monitoring/2011/05/1220_0131_2.pdf. Accessed 27 July 2012 (in Japanese).

15. ICRP. Recommendations of the ICRP. ICRP Publication 26, Ann ICRP, 1977;1(3). 